\title{
Determinants and prevalence of depression in patients with chronic renal disease, and their caregivers
}

This article was published in the following Dove Press journal: International Journal of Nephrology and Renovascular Disease 3 July 2017

Number of times this article has been viewed

\author{
Sana Hawamdeh \\ Aljawharah Mohammed \\ Almari \\ Asrar Salem Almutairi \\ Wireen Leila T Dator \\ College of Nursing, Princess Nourah \\ Bint Abdulrahman University, Riyadh, \\ Saudi Arabia
}

Introduction: This study explored the prevalence of depression among the patients with chronic kidney disease and their caregivers and its association to their demographic profile.

Methods: A descriptive, correlational, cross-sectional study that used the Hamilton rating scale tool to assess the prevalence of depression among 226 patients undergoing hemodialysis and 105 of their caregivers in a hospital in Saudi Arabia.

Results: Patients with chronic renal disease and their caregivers experience depression at varying levels. Depression was positively associated with the socioeconomic and marital status of the patients. Socioeconomic status of the caregivers was seen to be associated with their depression. Conclusion: Depression is highly prevalent among patients with chronic renal disease and their caregivers.

Keywords: caregivers, chronic renal disease, depression

\section{Introduction}

Patients and their families experience many different kinds of stress during the duration of their illness and treatment. Kidney disease is among the high-stress illnesses because of the chronicity of the disease and its long-term treatment. The patients suffer for years enduring discomfort and disruption to life as they spend hours undergoing dialysis treatments as long as they live. The illness also causes stress on the families of the patients because the treatment is life-time that requires constant and frequent visits to the hospital aside from the financial costs incurred and the change in family roles it brings about. Families also experience mental stress as they support their loved ones go through the process of illness and treatment. The presence of constant stress may lead to clinical depression when not recognized and managed appropriately.

The prevalence of renal diseases is high and growing in the gulf region. ${ }^{1}$ It has been noted that patients with renal disease suffer higher rates of depression including their caregivers who also suffer from mental stress. ${ }^{1,2}$ In Saudi Arabia, kidney diseases are among the top causes of morbidity and mortality. Statistics have shown that the prevalence of kidney diseases in the Kingdom is constantly increasing. ${ }^{3}$ It can be gleaned that the high prevalence of kidney diseases in the Kingdom may also indicate high prevalence of depression associated to these diseases; however, the attention is mostly focused on the management of the kidney disease rather than the associated depression. This study was done to explore the prevalence of depression among these patients with kidney diseases and their caregivers as well. Depression is as debilitating as the kidney disease itself and should be given the same amount of consideration. It
Correspondence: Sana Hawamdeh College of Nursing, Princess Nourah Bint Abdulrahman University

Al Imam Abdullah Ibn Saud Ibn Abdul Aziz Road, King Khalid International Airport, Riyadh, Saudi Arabia Email hawamdehs@gmail.com 
is considered to be the second most incapacitating and economically costly illness worldwide. Depression that is not managed affects the treatment and leads to poor prognosis of chronic kidney disease (CKD). ${ }^{4}$

\section{Methods}

This is a cross-sectional descriptive exploratory study that focused on the prevalence of depression among the patients with kidney failure and their caregivers. It also looked into the association of the demographic profiles and the prevalence of depression for both the patients with kidney failure and their caregivers.

\section{Participants}

The study included 226 patients and 105 caregivers. The participants included both the patients diagnosed with kidney disease and their caregivers from their families. All the patients and caregivers who met the inclusion criteria were included in the study. These patients included those diagnosed with chronic renal failure for at least 6 months; and who are on maintenance hemodialysis (HD) for at least 3 months. Patients with a history of depressive illness before the onset of renal failure, clinically and pathologically diagnosed cases of dialysis disequilibrium syndrome, hepatic or uremic encephalopathy and patients with any neurological deficit (such as stroke and cerebral hemorrhage) were excluded from the study. The participants also included the caregivers of these patients. These caregivers are members of their families and who have not been diagnosed of depressive symptoms prior to the time they started providing care for the patient. Both patients and caregivers were at least 18 years old. These criteria were strictly followed to control potential bias and confounders.

The study received ethical approval of the Institutional Review Board at King Fahed Medical City, Riyadh, Saudi Arabia. Eligible patients and caregivers were approached by researchers at the site. After an explanation of the study, written informed consent were obtained from each patient and caregiver. Patients were able to access research staff members who are not in charge of their treatment to withdraw from the study at any time.

\section{Instrument}

Hamilton rating scale for depression (HAM-D) was used to screen the severity of depression. ${ }^{5}$ The questionnaire was administered according to the interview guide for the HAM-D. The degree of depression was classified as normal if with a score $<6$, scores from 7 to 17 as slightly depressed, from 18 to 24 as moderately depressed, and $>25$ as seriously depressed. The use of the HAM-D has been systematically evaluated in Arab countries. Hamdi et al concluded, in their study, that the HAM-D is sensitive to the severity of depression in the United Arab Emirates (UAE) culture. Saudi being an Arab and Islamic country, like the UAE, has very closely similar culture. ${ }^{6}$

\section{Results \\ Depression and profile of patients}

Table 1 presents the profile of the participants of the study. The participants of the study were composed of $51 \%$ male and $49 \%$ female. Majority (61\%) of them were married, $17 \%$ were single, $8 \%$ were divorced, and $15 \%$ were widowed. A total of $77 \%$ were not employed. Majority (57\%) of them had middle income, $35 \%$ had low income, and $7.9 \%$ had high income. About $71 \%$ of the participants had no family history of renal failure.

The percentage distribution of the prevalence of depression assessed through the use of the HAM-D tool among the participants with renal failure showed that $28 \%$ of the participants had mild depression, $26 \%$ moderate depression, $8 \%$ severe depression, and $7 \%$ very severe. Thirty-one percent of the participants were assessed to be normal (Table 2). Among the demographic profile of the patients, the socioeconomic status (SES) and the marital status were found to be

Table I Baseline characteristics of the renal failure patients

\begin{tabular}{ll}
\hline Variable & $\mathbf{N}(\%)$ \\
\hline Gender & $116(51.3)$ \\
Male & $110(48.6)$ \\
Female & \\
Marital status & $38(16.8)$ \\
Single & $137(60.6)$ \\
Married & $17(7.5)$ \\
Divorced & $34(15)$ \\
Widow & \\
Employment status & $53(23.5)$ \\
Employed & $173(76.5)$ \\
Unemployed & \\
Socioeconomic level & $80(35.3)$ \\
Low & $128(56.6)$ \\
Middle & $18(7.96)$ \\
High & \\
Family history of renal failure & $65(28.7)$ \\
Yes & $161(71.2)$ \\
No & \\
Duration of dialysis session (hours) & $1(0.4)$ \\
2 & $84(37.2)$ \\
3 & $67(29.6)$ \\
$3-3.5$ & $74(32.7)$ \\
4 &
\end{tabular}


associated with depression among renal failure patients with a $p$-value of $<0.05$ level of significance (Table 3 ).

\section{Caregivers}

Among the 105 caregivers, most were females (62\%).

The majority of the caregivers were unemployed (58\%) and belonged to the middle socioeconomic class (69.5\%). Majority of them were married (57\%) and $8 \%$ were divorced or widowed (Table 4). Using the same assessment tool for depression, slightly more than half of the caregivers were assessed to also have depression (53\%). Among these, 31\% had mild depression, $14 \%$ had moderate depression, $8 \%$ had severe depression, but none of them were found to have very severe depression (Table 5). Depression was found to be significantly associated with SES with a $p$-value of 0.05 level of significance (Table 6) similar to the results found among the patients. Marital status that was found to be significantly correlated with depression among the patients, however, did not show significant correlation with depression among the caregivers. Further analysis showed no significant correlation

Table 2 Distribution of depression by HAM-D among the renal failure patients

\begin{tabular}{ll}
\hline Category & N (\%) \\
\hline Normal & $71(31.4)$ \\
Mild & $64(28.3)$ \\
Moderate & $58(25.6)$ \\
Severe & $18(7.96)$ \\
Very severe & $15(6.6)$ \\
\hline
\end{tabular}

Abbreviation: HAM-D, Hamilton rating scale for depression. between the prevalence of depression among the patients and their caregivers.

\section{Discussion}

\section{Prevalence of depression among the patients}

Among the participants with kidney failure, $70 \%$ of them were found to have depression at varying levels. This finding is consistent with the findings of previous studies conducted among patients with CKD where depression was shown to be associated with the disease. The risk of depression among patients with end-stage renal disease (ESRD) was found to be four times higher than that in the general population. ${ }^{7}$ Several studies done in various countries showed high prevalence of

Table 4 Characteristics of caregivers of renal failure patients

\begin{tabular}{ll}
\hline Variables & N (\%) \\
\hline Gender & \\
Male & $40(38)$ \\
Female & $65(61.9)$ \\
Employment status & \\
Employed & $44(41.9)$ \\
Unemployed & $61(58)$ \\
Socioeconomic level & \\
Low & $25(23.8)$ \\
Middle & $73(69.5)$ \\
High & $7(6.7)$ \\
Marital status & \\
Single & $37(35.2)$ \\
Married & $60(57)$ \\
Divorced & $4(3.8)$ \\
Widowed & $4(3.8)$ \\
\hline
\end{tabular}

Table 3 Determinants of depression among renal failure patients

\begin{tabular}{llllll}
\hline Variable & Normal & Mild & Moderate & Severe & Very \\
severe
\end{tabular}


depression at varying degrees among patients undergoing HD in Pakistan and Iran. ${ }^{8-11}$

According to many studies, depression seen in CKD patients can be attributed to several factors that include the reaction to the diagnosis and the nature of the treatment that the patient will undergo for a lifetime and the effect of these long-term treatments, such as compromised quality of life, job loss, and financial burden to the patient and the family. ${ }^{9-13}$ These reactions are compounded by the impact of depression, which is recognized to be an incapacitating disorder. The person suffering from depression further manifest their inability to perform their daily activities, such as the way they think, eat, sleep, and work. Symptoms can range from fatigue, feelings of hopelessness, restless, headaches, and suicide attempts among others. ${ }^{14}$ The symptoms of depression among these patients complicate their illness, affect their compliance to treatment, and their ability to cope. In a study conducted by Hedayati et al, they showed that death is twice as likely among ESRD patients on chronic HD with depression as compared with those without depression. ${ }^{2}$ They also mentioned that patients undergoing HD who were diagnosed with depression are at risk for a 30\% increase in both cumulative hospital days and number of hospitalizations. Although depression has been found to be associated with $\mathrm{CKD}$, it is despondent to note that it is not well-addressed

Table 5 Distribution of depression among caregivers of renal failure patients

\begin{tabular}{ll}
\hline Category & N (\%) \\
\hline No depression & $49(47)$ \\
Mild & $33(31.4)$ \\
Moderate & $15(14.4)$ \\
Severe & $8(7.7)$ \\
\hline
\end{tabular}

among these patients. ${ }^{2}$ Most of the time, the patient and the family are more focused on the compliance to the treatment and do not recognize symptoms of depression as equally important. Findings of this study and other previous studies have shown the high prevalence of depression among patients with ESRD; ${ }^{3,7-43}$ hence, appropriate attention and management should be considered and integrated to address depression among these patients with ESRD.

Depression is the most widely acknowledged psychosocial factor seen in patients with $\mathrm{CKD}$, and it has been associated with a poor outcome. Major depression occurs in $20 \%-30 \%$ of patients facing impending dialysis. The etiology of depression in this case is complex. Kidney disease causes exposure to many physical and psychological stressors: starting from severe symptoms from internal organs, pain, and insomnia, through the necessity to submit to a dietary regime, systematic dialysis, or change in lifestyle or so far played roles and deterioration of the quality of life. However, the development of depression adversely influences the general health of a patient and also the patient-doctor cooperation in treatment; it increases the duration and frequency of hospitalization and may cause cessation of kidney replacement therapy; it causes an increase in mortality in dialyzed patients and also increases the risk of committing suicide. ${ }^{15-19}$ Kidney disease itself is associated with a high frequency of both physical and psychological complications, with depression being at the top of the list with a frequency of $61.1 \%$. It has been documented that depression worsens the perceptions of patients for their well-being, which ultimately affects their compliance with treatment regimens. ${ }^{20-22}$

Depression in CKD patients may be undertreated. Watnick et al reported that just $16 \%$ of HD patients with depression were receiving treatment. Addressing depression in CKD

Table 6 Determinants of depression among caregivers of renal failure patients

\begin{tabular}{|c|c|c|c|c|c|}
\hline Variable & Normal & Mild & Moderate & Severe & p-value \\
\hline \multicolumn{6}{|l|}{ Gender } \\
\hline Male & $18(45)$ & $15(37.5)$ & $4(10)$ & $3(7.5)$ & 0.6 \\
\hline Female & $31(48.4)$ & $17(26.6)$ & II (I7.2) & $5(7.8)$ & \\
\hline \multicolumn{6}{|l|}{ Marital status } \\
\hline Single & $19(52.8)$ & $9(25)$ & $6(16.7)$ & $2(5.6)$ & 0.63 \\
\hline Married & $26(43.3)$ & $22(36.7)$ & 7 (II.7) & $5(8.3)$ & \\
\hline Divorced & $3(75)$ & $0(0)$ & I (25) & $0(0)$ & \\
\hline Widowed & I (25) & I (25) & I (25) & I (25) & \\
\hline \multicolumn{6}{|c|}{ Employment status } \\
\hline Employed & $19(44)$ & I 8 (4I.7) & $4(9.3)$ & $2(4.6)$ & 0.14 \\
\hline Unemployed & $30(49.2)$ & $14(22.9)$ & II (I8) & $6(9.8)$ & \\
\hline \multicolumn{6}{|c|}{ Socioeconomic status } \\
\hline Low & $6(24)$ & $8(32)$ & $8(32)$ & $3(12)$ & 0.05 \\
\hline Middle & $39(54.2)$ & $22(30.6)$ & $7(9.7)$ & $4(5.6)$ & \\
\hline High & $4(57)$ & $2(28.6)$ & $0(0)$ & I (I8.3) & \\
\hline
\end{tabular}


patients is important because it may improve other adverse outcomes, including poor nutritional status and treatment compliance associated with $\mathrm{CKD}^{23}$ Very few studies have focused on the treatment of depression and anxiety disorders in patients with CKD. The prevalence of depressive episodes in CKD patients is even higher than reported for other chronic diseases, such as diabetes mellitus and congestive heart failure. ${ }^{16,24-26}$ Patients on chronic HD with depression are twice as likely to die or require hospitalization within a year when compared with those without depression and are at risk for a $30 \%$ increase in both cumulative hospital days and number of hospitalizations. ${ }^{2,17}$

\section{Demographic profile and depression}

\section{Marital status}

This study found an association between the economic status and the marital status of the patients and the prevalence of depression. Similar findings have been reported by various studies that depression was higher among married patients who underwent peritoneal dialysis (PD) and HD. ${ }^{10}$ Another study reported that within the patients group, marital status $(p<0.001)$ was found to be positively associated with moderate-to-severe depression in patients. Poorer marital adjustment has been seen from patients on HD compared with healthy individuals. Poor marital adjustment had been linked with depressive symptoms and anxiety. ${ }^{27}$ In a study done in Canada, $20 \%$ of the spouses of dialysis patients had "significant depressive symptoms." 28 Most studies performed within families of HD patients showed that more than half of the couples had evidence of marital disruption. ${ }^{29}$ Chowanec and Binik showed that dialysis patients and spouses had strong links between psychological distress and perceptions of marital strain. ${ }^{28}$ Chronic illness such as CKD in a couple may cause tension on usual marital roles. The patient's ability to work may be compromised and further alters the individual's roles as couples. Furthermore, the patients' negative emotions may be bound for the spouse. The spouses who become caregivers may experience depression or hostility. Ultimately, sexual dysfunction can cause disruption in the dynamics of the relationship. ${ }^{29,30}$

\section{Income and SES}

Low income is significantly associated with depression among the patients in this study. The same results have been found from various studies. In a study conducted in Saudi Arabia, high percentage (75.7\%) of depressed patients with PD had low monthly income (<7500 Saudi Riyals); this result is also similar to the findings of the studies done among patients on HD that showed depression was higher among HD patients who had lower economic status. ${ }^{31,32} \mathrm{CKD}$ treatment is debilitating and causes a lot of strain on the patient including their families. Financial strain can seriously impact the compliance to treatment and meeting the family's economic needs. However, studies that have assessed the relationship between survival and SES in patients with the CKD have suggested that higher SES was associated with improved survival, regardless of race. ${ }^{33}$

\section{Depression among the caregivers}

Zyada et al in their study done in Egypt among caregivers reported that caregivers of patients with terminal organ failure (hepatic, cardiac, and renal) experience high levels of burden, severe anxiety, and mild depression. Predictors of anxiety, depression, and burden include being the main caregiver, duration of caregiving, the caregiver's employment status, perceived health, and impact on social activities. ${ }^{34}$ The caregivers face many difficulties including change in the sleep pattern, health, social activity, and change in holiday plans. Both patients and caregivers spend at least 3 days a week on dialysis, which restricts their social life and creates a feeling of dependency on the dialysis center. ${ }^{35}$ Hence, they are left with no choice but to make many modifications to their life style. ${ }^{36}$

Research has exposed that immense physiological, psychological, and financial costs associated with informal caregiving have increased stress and depression, worsened social and family life, physical illness, increased feelings of burden, and decreased quality of life. ${ }^{37-40}$ Caregivers miss days of work and more likely to quit or retire early. ${ }^{41}$

Caregivers for patients undergoing dialysis also experience depression, anxiety, fatigue, social isolation, relationship strains, physical, emotional, and financial strain. ${ }^{5,6,15,20,21,42}$ These caregivers who are expected to provide complex technical regimens experience stress from the added responsibility of taking over the medical treatments, dietary requirements, clinical appointments, and psychosocial issues. ${ }^{16,17,19}$ Despite these burden experienced by caregivers, they have not been provided the needed management to control depression and other impact of the caregiving burden. Depression among patients and caregivers have been neglected and under-prioritized over the patients' management of CKD.

Studies done among caregivers of patients with chronic illnesses showed that emotional difficulties, such as depression, various anxiety-related symptoms, excessive medication use, and impaired quality of life, were found to be associated with caregiving for patients with chronic diseases. ${ }^{5,6,20,42}$ In these studies, caregivers who experienced these difficulties 
were found to have higher mortality rate than the noncaregiving controls. Report also revealed that only $56 \%$ of the caregivers have the knowledge on their risk for depression. ${ }^{43}$

Caregiving burden from chronic diseases such as CKD is experienced by those directly responsible for giving care, especially for patients who are family members. It has been noted that caregiver burden worsens when the patient has limited ability to care for himself due to functional and cognitive impairment secondary to the chronic disease. Other factors that increase the risk of depression among caregivers include the relationship between the caregiver and their career and the patient, the deteriorating behavior and psychological stance of the patient, gender, and adverse life events. ${ }^{17,19}$

\section{Conclusion}

In conclusion, $\mathrm{CKD}$ patients and their caregivers need to be educated on the high prevalence of depression among themselves and recognize the surrounding conditions that increase its likelihood to be developed, at the same time understand and consider its impact on their marital, social, and economic status.

\section{Recommendation}

Referral for psychological and social support for both the patient and the spouse caregiver should become an integral part of the management for patients with CKD even before the onset of depression.

The life-time journey to the HD centers can become innovative and creative in such a way that it becomes a venue for discovering or enhancing the marital relationship and support. It maybe possibly done when the HD venue is able to revolutionize treatment sessions into recreational and productive session at least for the caregiver.

\section{Acknowledgments}

The authors would like to acknowledge the Princess Nourah Bint Abdulrahman University, Riyadh, Kingdom of Saudi Arabia for the support granted to the researchers. Also they would like to thank the Bashair Abdulla Almugren of the College of Nursing, PNU.

\section{Disclosure}

The authors report no conflicts of interest in this work.

\section{References}

1. Hassanien AA, Al-Shaikh F, Vamos EP, Yadegarfar G, Majeed A. Epidemiology of end-stage renal disease in the countries of the Gulf Cooperation Council: a systematic review. JRSM Short Rep. 2012;3(6):1-21.
2. Hedayati SS, Bosworth HB, Briley LP, et al. Death or hospitalization of patients on chronic hemodialysis is associated with a physician-based diagnosis of depression. Kidney Int. 2008;74(7):930-936.

3. Hawamdeh S, Dator, Wireen LT, Abunab HY. Prevalence of depression among Arab women with type 2 diabetes: a systematic review and meta-analysis. Health. 2016;8(7):650-657.

4. Assefa B, Duko B, Ayano G, Mihretie G. Prevalence and factors associated with depressive symptoms among patient with Chronic Kidney Disease (CKD) in Black Lion Specialized Hospital and Saint Paulo's Hospital Millennium Medical College, Addis Ababa, Ethiopia: Cross Sectional Study. J Psychiatry. 2016;19:390.

5. Hamilton M. Development of a rating scale for primary depressive illness. Br J Soc Clin Psychol. 1967;6(4):278-296.

6. Hamdi E, Amin Y, Abou-Saleh MT. Performance of the Hamilton depression rating scale in depressed patients in the United Arab Emirates. Acta Psychiatrica Scandinavica. 1997;96(6):416-423.

7. Lopes AA, Bragg J, Young E, et al. Depression as a predictor of mortality and hospitalization among hemodialysis patients in the United States and Europe. Kidney Int. 2002;62(1):199-207.

8. Turkmen K, Yazici R, Solak Y, et al. Health-related quality of life, sleep quality, and depression in peritoneal dialysis and hemodialysis patıents. Hemodial Int. 2012;16(2):198-206.

9. Klaric D, Klaric V. Depression in end stage renal disease: comparison between patients treated with hemodialysis and peritoneal dialysis. $J$ Life Sci. 2012;6(5):582-586.

10. Saeed Z, Ahmad AM, Shakoor A, Ghafoor F, Kanwal S. Depression in patients on hemodialysis and their caregivers. Saudi J Kidney Dis Transpl. 2012;23(5):946-952.

11. Eghbali M, Shahqolian N, Nazari F, Babaee S. Comparing problems of patients with chronic renal failure undergoing hemodialysis and peritoneal dialysis referring to medical university's hospitals. Iran $J$ Nurs Midwifery Res. 2009;14(1).

12. Aghanwa HS, Morakinyo O. Psychiatric complications of hemodialysis at a kidney center in Nigeria. J Psychosom Res. 1997;42(5):445-451.

13. Levey AS, Bosch JP, Lewis JB, Greene T, Rogers N, Roth D. A more accurate method to estimate glomerular filtration rate from serum creatinine: a new prediction equation. Ann Intern Med. 1999;130(6):461-470.

14. Tarleton EK, Littenberg B. Magnesium intake and depression in adults. J Am Board Fam Med. 2015;28(2):249-256.

15. Amira O. Prevalence of symptoms of depression among patients with chronic kidney disease. Niger J Clin Pract. 2011;14(4):460-463

16. Kimmel PL, Peterson RA. Depression in end-stage renal disease patients treated with hemodialysis: tools, correlates, outcomes, and needs. Semin Dial. 2005;18(2):91-97.

17. Hedayati SS, Grambow SC, Szczech LA, Stechuchak KM, Allen AS, Bosworth HB. Physician-diagnosed depression as a correlate of hospitalizations in patients receiving long-term hemodialysis. Am J Kidney Dis. 2005;46(4):642-649.

18. Joshi,VD. Quality of life in end stage renal disease patients. World $J$ Nephrol. 2014;3(4):308-316.

19. Lopes AA, Albert JM, Young EW, et al. Screening for depression in hemodialysis patients: associations with diagnosis, treatment, and outcomes in the DOPPS. Kidney Int. 2004;66(5):2047-2053.

20. Finkelstein FO, Finkelstein SH, Wuerth D, Shirani S, Troidle L. Effects of home hemodialysis on health related quality of life measures. Semin Dial. 2007;20(3):265-268.

21. Kimmel PL, Levy NB. Psychology and rehabilitation. In: Daugirdas JT, Blake PG, Ing TS, editors. Handbook of Dialysis. 3rd ed. Philadelphia: Lippincott Williams and Wilkins; 2001:413-419.

22. Fan L, Sarnak MJ, Tighiouart H, et al. Depression and all-cause mortality in hemodialysis patients. Am J Nephrol. 2014;40(1):12-18.

23. Watnick S, Kirwin P, Mahnensmith R, Concato J. The prevalence and treatment of depression among patients starting dialysis. Am J Kidney Dis. 2003;41(1):105-110.

24. Cohen S, Kimmel PL. Nutritional status, psychological issues and survival in hemodialysis patients. Contrib Nephrol. 2007;155:1-17). 
25. Anderson RJ, Freedland KE, Clouse RE, Lustman PJ. The prevalence of comorbid depression in adults with diabetes. Diabetes Care. 2001;24(6):1069-1078.

26. Jiang W, Alexander J, Christopher E, et al. Relationship of depression to increased risk of mortality and rehospitalization in patients with congestive heart failure. Arch Intern Med. 2001;161(15):1849-1856.

27. Tavallaii S, Nemati E, Vishteh H, et al. Marital adjustment in patients on long-term hemodialysis: a case-control study. Iran J Kidney Dis. 2009;3(3):156-161.

28. Chowanec GD, Binik YM. End stage renal disease and the marital dyad: an empirical investigation. Soc Sci Med. 1989;28(9):971-983.

29. Steele TE, Wuerth D, Finkelstein S, et al. Sexual experience of the chronic peritoneal dialysis patient. J Am Soc Nephrol. 1996;7(8):1165-1168.

30. Palmer BF. Sexual dysfunction in men and women with chronic kidney disease and end-stage kidney disease. Adv Ren Replace Ther. 2003;10(1):48-60.

31. Pramiladevi R, Goornavar SM, Kora S. Depression in patients on hemodialysis in Bagalkot. Medica Innovatica. 2012;1(1):5-11.

32. Hedayati SS, Yalamanchili V, Finkelstein FO. A practical approach to the treatment of depression in patients with chronic kidney disease and end-stage renal disease. Kidney Int. 2012;81(3):247-255.

33. Robinson BM, Joffe MM, Pisoni RL, Port FK, Feldman HI. Revisiting survival differences by race and ethnicity among hemodialysis patients: the Dialysis Outcomes and Practice Patterns Study. J Am Soc Nephrol. 2006;17(10):2910-2918.

34. Zyada F, Sheta M, El Degwi H, Saad R. Anxiety, depression, and strain among caregivers of terminally ill patients. Egypt J Psychiatr. 2013;34:77-84
35. Fast J, Keating N. Informal Caregivers in Canada: A Snapshot. Health Services Division, Health Policy and Communications Branch, Health Canada; Edmonton, AB, 2001.

36. Sezer MT, Eren I, Ozcankaya R, Civi I, Erturk J, Ozturk, M. Psychological symptoms are greater in caregivers of patients on hemodialysis than those of peritoneal dialysis. Hemodial Int. 2003;7(4):332-337.

37. Clyburn LD, Stones MJ, Hadjistavropoulos T, Tuokko H. Predicting caregiver burden and depression in Alzheimer's disease. J Gerontol B Psychol Sci Soc Sci. 2000;55(1):S2-S13

38. Cameron JI, Franche RL, Cheung AM, Stewart DE. Lifestyle interference and emotional distress in family caregivers of advanced cancer patients. Cancer. 2002;94(2):521-527.

39. Vitaliano PP, Zhang J, Scanlan JM. Is caregiving hazardous to one's physical health? A meta-analysis. Psychol Bull. 2003;129(6): 946-972.

40. Argimon JM, Limon E, Vila J, Cabezas C. Health-related quality of life in carers of patients with dementia. Fam Pract. 2004;21(4): 454-457.

41. Ho A, Collins SR, Davis K, Doty MM. A look at working-age caregivers' roles, health concerns, and need for support. Issue Brief (Commonw Fund). 2005;854:1-12.

42. Khaira A, Mahajan S, Khatri P, Bhowmik D, Gupta S, Agarwal SK. Depression and marital dissatisfaction among Indian hemodialysis patients and their spouses: a cross-sectional Study. Renal Fail. 2012;34(3):316-322.

43. Tong A, Sainsbury P, Craig JC. Support interventions for caregivers of people with chronic kidney disease: a systematic review. Nephrol Dial Transplant. 2008;23(12):3960-3965.

\section{Publish your work in this journal}

The International Journal of Nephrology and Renovascular Disease is an international, peer-reviewed open access journal focusing on the pathophysiology of the kidney and vascular supply. Epidemiology, screening, diagnosis, and treatment interventions are covered as well as basic science, biochemical and immunological studies. The manuscript management system is completely online and includes a very quick and fair peer-review system, which is all easy to use. Visit http://www. dovepress.com/testimonials.php to read real quotes from published authors. 